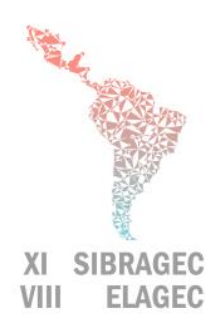

XI SIMPÓSIO BRASILEIRO DE GESTÃO E ECONOMIA DA CONSTRUÇÃO

VIII ENCUENTRO LATINOAMERICANO DE GESTIÓN Y ECONOMÍA DE LA CONSTRUCCIÓN

Do conhecimento à ação: práticas avançadas de gestão da produção

Londrina, Paraná, Brasil. 23 a 25 de Outubro de 2019

\title{
LEVANTAMENTO DE INDICADORES FINANCEIROS-CHAVE DA INCORPORAÇÃO IMOBILIÁRIA
}

\author{
AMARAL, Tatiana G. (1); QUEIROZ, Adriano Luiz S. (2) \\ (1) Universidade Federal de Goiás, Escola de Engenharia Civil e Ambiental, (62) 981680902, e-mail: \\ tatiana_amaral@hotmail.com \\ (2) Universidade Federal de Goiás, Escola de Engenharia Civil e Ambiental, (62) 98472-3999, e-mail: \\ adrianoluiz.131@gmail.com
}

\begin{abstract}
Real estate development is the business activity characterized by realty production that will include activities from the planning of a set of properties and their commercialization during construction. When we compare the indicators of this area with other types of companies, we realize that it is a subject still relatively little addressed in studies and, when studied, there are more references for Construction than for Real Estate Development. In this sense, a case study was conducted through semi-structured interviews with the purpose of raising the financial indicators, those that are most often taken into account at a strategic level (launch or continuation of a construction, reassess sales and competition), the degree of importance and the degree of difficulty in measuring these performance indicators. During the survey, it was found that the real estate developer analyzed has $60 \%$ of its indicators with the degree of importance five, the largest of the adopted scale, and has in its measurement degree the average measurement difficulty of 3.06. For market validation, seven of the eight common indicators with ADEMI-GO surveys have a degree of importance greater than four. The main difficulty in measuring the indicators raised is the excess of manual labor; in other words, the lack of integration between the Company's platforms that would compile the various input data into a summary, a single panel containing all indicators.
\end{abstract}

Keywords: Decision making, System of indicators, Financial indicators, Real Estate Development.

\section{INTRODUÇÃO}

Os indicadores de desempenho são importantes ferramentas para o planejamento, na tomada de decisão e desenvolvimento de políticas, para a interpretação de dados, definição de metas e medição do sucesso em alcançá-las, facilitando assim a comunicação e entendimento sobre uma área. Além disso o uso de indicadores permite a identificação e avaliação de tendências e a comparação de resultados em diferentes contextos (BELLEN, 2005).

Com a evolução dos estudos, observou-se uma tendência mundial, por parte de executivos, sobre o que se mensurar como medida de desempenho, intensificando a necessidade de definir o que é importante em meio ao superávit de indicadores (NEELY; BOURNE, 2000; LIMA; PONTE, 2006). Segundo Rosa et al. (2013), apesar das dificuldades encontradas em sua aplicação, a mensuração de desempenho contribui, significativamente, nos processos de tomada de decisão.

A existência de um número significativo de indicadores pode aumentar a dificuldade que as empresas têm em definir seus indicadores-chave. Segundo Lima e Ponte (2006), é considerado um fator-chave tudo aquilo que pode influenciar a eficácia da implementação do modelo em uma organização, sendo este o que de fato reflete os seus atributos na competição em um mercado dinâmico que demanda constante atualização dos sistemas de medição (KENNERLEY; NEELY, 2002). Em paralelo surgiu

AMARAL, T. G.; QUEIROZ, A. L. S. Levantamento de indicadores financeiros-chave da incorporação imobiliária. In: SIMPÓSIO BRASILEIRO DE GESTÃO E ECONOMIA DA CONSTRUÇÃO, 11., 2019, Londrina. Anais [...]. Porto Alegre: ANTAC, 2019. Disponível em:

https://www.antaceventos.net.br/index.php/sibragec/sibragec2019/paper/view/484 
a noção de que as medidas que fossem definidas com precisão ofereciam um excelente respaldo para metas factíveis e para o alinhamento estratégico da empresa.

O uso da medição como ferramenta para o gerenciamento organizacional decorre de problemas culturais e estigmas resultantes de uma prática indevida. Segundo Lima e Ponte (2006), é comum os gestores medirem o que é mais fácil ou mais urgente, acarretando em erros ou em simplificações. Muitas vezes medem para simplesmente controlar, gerando uma prática voltada especificamente para o cumprimento das metas, e não para melhoria.

Dessa forma, o objetivo desse trabalho é levantar os indicadores financeiros-chave utilizados para a tomada de decisão e suas dificuldades de medição em uma Incorporadora e Construtora goiana. A principal contribuição da pesquisa foi a realização do levantamento em um segmento do mercado tradicional que se baseia nos aspectos financeiros para a tomada de decisão e planejamento de ações.

\section{MÉTODO DE PESQUISA}

\subsection{Levantamento de dados}

O levantamento de dados foi subsidiado pelo roteiro de entrevista semiestruturada adaptado de Cândido (2015) (Apêndice A), com enfoque nos indicadores financeiros nas etapas de viabilidade econômica-financeira, planejamento e construção do empreendimento.

Para a interpretação dos dados levantados na entrevista foi solicitado à empresa que a mesma indicasse qual o grau de importância que ela atribuía a cada situação de medição de desempenho (A) e qual o grau de utilização do indicador pela empresa (B).

A escala adota pelos pesquisadores foi de 1 a 5, sendo 1 considerado sem importância (A)/pouca dificuldade de medição (B) e 5 extremamente importante (A)/muita dificuldade de medição (B). Os resultados foram tabulados e representados em gráficos apresentados no tópico 3.

Por fim, realizou-se a análise documental de medições e relatórios apresentados pela empresa. A análise documental possibilitou validar as impressões e opiniões levantadas durante a entrevista e permitiu reconstruir informações relevantes para responder aos questionamentos da pesquisa. Para tal, deve-se atentar que uma análise confiável de dados delimita as questões da pesquisa, recorrendo a fontes, pessoas e grupos de modo a obter um ponto de vista global sobre o assunto (CELLARD, 2010).

Os dados coletados foram tratados em planilhas contendo os indicadores coletados da Empresa de cada etapa da incorporação, em tabelas contendo as reincidências e unicidades, posteriormente analisados graficamente.

Também foram coletados os indicadores da Associação das Empresas do Mercado Imobiliário (ADEMI) e os do Sindicato da Indústria da Construção (SINDUSCON), os quais estão apresentados no Quadro 1. 


\section{Quadro 1 - Indicadores da ADEMI e SINDUSCON}

\begin{tabular}{|c|c|c|}
\hline \multicolumn{2}{|c|}{$\begin{array}{l}\text { Indicadores separados por tipologia, segmento e região } \\
\text { Fluxo Descendente }\end{array}$} & $\begin{array}{l}\text { Indicadores } \\
\text { Econômicos }\end{array}$ \\
\hline $\begin{array}{l}\begin{array}{l}\text { Evolução da } \\
\text { porcentagem }\end{array} \\
\end{array}$ & $\begin{array}{l}\text { Número total de vagas de } \\
\text { garagem }\end{array}$ & CUB - GO \\
\hline Fase da Obra & $\begin{array}{l}\text { Porcentagem de unidades } \\
\text { vendidas }\end{array}$ & IPC - GOIÂNIA \\
\hline $\begin{array}{l}\text { Gráficos de Vendas sobre } \\
\text { Ofertas (VSO) }\end{array}$ & $\begin{array}{l}\text { Preço em reais por metro } \\
\text { quadrado privativo }\end{array}$ & INPC \\
\hline $\begin{array}{l}\text { Metragem quadrada da Área } \\
\text { Privativa }\end{array}$ & $\begin{array}{l}\text { Preço em reais por metro } \\
\text { quadrado privativo médio }\end{array}$ & IGP-M \\
\hline $\begin{array}{l}\text { Metragem quadrada da Área } \\
\text { Privativa total }\end{array}$ & $\begin{array}{l}\text { Previsão de Unidades de } \\
\text { Lançamentos }\end{array}$ & INCC \\
\hline $\begin{array}{l}\text { Metragem quadrada de área } \\
\text { privativa média }\end{array}$ & $\begin{array}{l}\text { Quantidade de Blocos por } \\
\text { Empreendimento }\end{array}$ & IPC \\
\hline $\mathrm{N}^{\mathrm{o}}$ de Unidades por andar & $\begin{array}{ll}\text { Quantidade } & \text { de } \\
\text { Empreendimentos } & \\
\end{array}$ & IGP-DI \\
\hline $\mathrm{N}^{\mathrm{o}}$ de Vendas por mês & $\begin{array}{l}\text { Quantidade de Unidades com } \\
\text { distratos }\end{array}$ & TR \\
\hline $\begin{array}{l}\text { Número de vagas de garagem } \\
\text { por unidade }\end{array}$ & $\begin{array}{l}\text { Quantidade de Unidades } \\
\text { disponíveis }\end{array}$ & POUPANÇA \\
\hline $\begin{array}{l}\text { Número total de unidades } \\
\text { Vendidas }\end{array}$ & Total de Unidades & SALÁRIO MÍNIMO \\
\hline
\end{tabular}

Fonte: Adaptado de ADEMI (2018) e SINDUSCON (2018).

\subsection{Critérios de seleção da empresa}

Os critérios para a seleção da empresa participante foram: o seu interesse em participar de estudos acadêmicos; a sua excelência no setor, dada por premiações; tempo de atuação no mercado, além de possui empreendimentos em execução para possibilitar o levantamento de dados para a pesquisa.

\subsection{Caracterização da empresa participante}

A Empresa selecionada está localizada em Goiânia e atua no mercado há 37 Anos.

Possui certificações ISO 9001 e PBQP-h nível A e empreendimentos que atendem a ABNT NBR 15575: 2013. A empresa possui mais de vinte milhões de metros quadrados construídos e quatro empreendimentos em construção em 2018. Os empreendimentos possuem as seguintes tipologias: Comercial, Residencial Médio/Alto Padrão e Empreendimentos Econômicos.

\subsection{Definição dos indicadores coletados}

A definição dos indicadores coletados está no Quadro 2. Foram definidos após a coleta de dados na empresa participante. 


\section{Quadro 2 - Indicadores da ADEMI e SINDUSCON}

\begin{tabular}{|c|c|c|}
\hline Indicador & Definição & Fonte \\
\hline Custo de Obra & $\begin{array}{l}\text { Custo global da construção: Valor mínimo que } \\
\text { pode ser atribuído à construção da edificação } \\
\text { para fins do disposto no art. } 32 \text {, da Lei } 4.591 / 64\end{array}$ & $\begin{array}{l}\text { Item } 3.8 \text { da NBR } \\
12721: 2006\end{array}$ \\
\hline Distrato & $\begin{array}{l}\text { Ferramenta contratual para se desfazer de uma } \\
\text { unidade, extinguindo o vínculo criado pelo } \\
\text { contrato }\end{array}$ & $\begin{array}{lr}\text { DE } & \text { FREITAS; } \\
\text { ROSA; ALENCAR, } \\
2016\end{array}$ \\
\hline $\begin{array}{l}\text { Evolução de } \\
\text { lucro líquido }\end{array}$ & $\begin{array}{l}\text { Acompanhamento do lucro líquido acumulado } \\
\text { mês a mês }\end{array}$ & Empresa participante \\
\hline Lucratividade & $\begin{array}{l}\text { Relação entre o valor do lucro líquido e o valor } \\
\text { das vendas. É um número percentual }\end{array}$ & SEBRAE \\
\hline Lucro líquido & $\begin{array}{l}\text { O Lucro Líquido é o lucro subtraído das } \\
\text { despesas financeiras, dos impostos sobre a } \\
\text { renda, da depreciação e amortização e os juros }\end{array}$ & Empresa participante \\
\hline Margem & $\begin{array}{l}\text { Margem de lucro da empresa, em termos de } \\
\text { lucratividade }\end{array}$ & Empresa participante \\
\hline Margem líquida & $\begin{array}{l}\text { Porcentagem referente ao Lucro líquido em } \\
\text { relação a Receita líquida }\end{array}$ & Empresa participante \\
\hline $\begin{array}{l}\text { Metragem } \\
\text { quadrada } \\
\text { construída }\end{array}$ & $\begin{array}{l}\text { Soma das áreas cobertas e descobertas reais, } \\
\text { situadas nos diversos pavimentos da edificação, } \\
\text { calculadas a partir do projeto arquitetônico } \\
\text { aprovado }\end{array}$ & $\begin{array}{l}\text { Item 3.7.1.4 da NBR } \\
12721: 2006\end{array}$ \\
\hline $\begin{array}{l}\text { Metragem } \\
\text { quadrada } \\
\text { privativa }\end{array}$ & $\begin{array}{l}\text { Áreas cobertas ou descobertas que definem o } \\
\text { conjunto de dependências e instalações de uma } \\
\text { unidade autônoma, cuja utilização é privativa } \\
\text { dos respectivos titulares de direito }\end{array}$ & $\begin{array}{l}\text { Item 3.7.2.1 da NBR } \\
12721: 2006\end{array}$ \\
\hline Produtividade & $\begin{array}{l}\text { Produtividade é a relação entre a despesa } \\
\text { administrativa e o faturamento }\end{array}$ & Empresa participante \\
\hline $\begin{array}{l}\text { ROE - Return } \\
\text { On Equity }\end{array}$ & $\begin{array}{l}\text { Em português: Retorno sobre o Patrimônio. } \\
\text { Percentual do retorno obtido pela divisão do } \\
\text { lucro líquido pelo patrimônio líquido obtidos } \\
\text { nas demonstrações contábeis das entidades }\end{array}$ & FREZATTI, 2006 \\
\hline TIR (a.a. e a.m.) & $\begin{array}{l}\text { Taxa de juros que anula o VPL do fluxo de caixa } \\
\text { de um investimento }\end{array}$ & $\begin{array}{l}\text { BARBIERI et al., } \\
2007\end{array}$ \\
\hline Valor Presente & $\begin{array}{l}\text { Valores de um fluxo de caixa descontados a } \\
\text { uma Taxa Mínima de Atratividade }\end{array}$ & $\begin{array}{l}\text { BARBIERI et al., } \\
2007\end{array}$ \\
\hline Valuation & $\begin{array}{l}\text { Valuation é o termo em inglês para "Avaliação } \\
\text { de Empresas". A avaliação mais comum é a } \\
\text { partir do valor dos ativos e o valor presente do } \\
\text { fluxo de caixa futuro }\end{array}$ & MARTINS, 2001 \\
\hline $\begin{array}{l}\text { Velocidade de } \\
\text { Vendas }\end{array}$ & $\begin{array}{l}\text { O índice de velocidade de vendas (IVV) } \\
\text { considera o tempo de exposição do produto no } \\
\text { mercado, sua localização, preço, tamanho, entre } \\
\text { outras características, e reflete o grau de } \\
\text { atratividade que o produto exerce sobre o } \\
\text { mercado }\end{array}$ & BARBOSA, 2015 \\
\hline Venda Bruta & Venda de unidades sem considerar os distratos & Empresa participante \\
\hline Venda Líquida & $\begin{array}{l}\text { Venda líquida é a venda de unidades menos o } \\
\text { VGV distratado }\end{array}$ & Empresa participante \\
\hline VGV $(\mathrm{R} \$)$ & $\begin{array}{l}\text { Valor Geral de Vendas. É o valor calculado pela } \\
\text { soma do valor potencial de venda de todas as } \\
\text { unidades de um empreendimento a ser lançado }\end{array}$ & GOLDMAN, 2004 \\
\hline
\end{tabular}

Fonte: Do autor. 


\section{RESULTADOS}

De acordo com os resultados levantados, a empresa possui 32 indicadores, sendo oito coincidentes com os dados da pesquisa da ADEMI. A empresa apontou a importância dos indicadores financeiros, pois é por meio deles que a mesma realiza projeções do novos lançamentos, obtêm noções de geração de caixa e estipula suas metas futuras. Além disso, utilizam os resultados dos indicadores financeiros para identificarem discrepâncias ao que foi planejado para a proposição de planos de ação.

A empresa reconhece que apenas o uso de indicadores financeiros não é o suficiente para a tomada de decisão e afirma que as áreas Financeira e de Planejamento de Obras devem estar sempre alinhadas com a sua estratégia.

Os indicadores financeiros utilizados pela empresa foram escolhidos a partir do planejamento estratégico, de processos críticos e de práticas de mercado. A controladoria da empresa foi responsável pela seleção/escolha dos indicadores financeiros, bem como por todo o processamento e análise das informações que são geradas pelos responsáveis de cada área (exemplo: analista comercial gera relatório de vendas). A empresa declarou que não identifica dificuldades para definição de quais são os indicadores financeiros devem ser adotados e estabeleceu a rotina de definir, medir e monitorar estes indicadores mensalmente.

A empresa coleta indicadores financeiros, relacionados ao custo real da obra, utilizando-se destas informações para se nortear e para comparar com o que foi definido na viabilidade inicial, a fim de verificar se a meta será atingida ou não.

Utilizam de informações de mercado para minimizar os erros nas projeções, como a pesquisa da ADEMI. A empresa acredita que é quase impossível obter exatidão do que foi planejado, mas que tem ferramentas suficientes que permitem estimar valores assertivos.

A principal dificuldade que a empresa tem para realizar a coleta e o processamento dos dados referentes aos indicadores financeiros é o excesso de trabalho manual, dificuldade esta que vem sendo minimizada por meio da automatização dos dados.

A empresa tem $60 \%$ dos seus indicadores com o grau de importância 5, o maior valor da escala adotada, e tem em sua medição grau de dificuldade de medição médio de 3,06. Para validação do mercado, 7 dos 8 indicadores em comum com as pesquisas da ADEMI-GO têm grau de importância superior a 4 .

Cinco dos 32 indicadores de caráter contábil levantados relacionam-se com as áreas de planejamento e controladoria da empresa e a principal dificuldade de se levantar estes dados é o excesso de trabalho manual, questão recorrente quando se trata de sistemas de medição de desempenho. A empresa busca sanar este problema por meio de automatização do banco de dados.

Pode-se constatar que os indicadores financeiros não estão relacionados apenas a uma área da empresa. Durante a pesquisa houve dificuldade em identificar a equipe responsável pelo monitoramento destes indicadores, visto que as áreas de contabilidade, viabilidade, planejamento de obras e novos empreendimentos e área comercial, mensuram esses dados. A falta do estabelecimento de uma única equipe responsável dificulta a medição, monitoramento e controle do sistema de indicadores.

A partir dos dados coletados foi possível elaborar a Figura 1, que compara o grau de importância e de dificuldade, em escala de 1 (pouco importante/fácil medição) a 5 (muito importante/difícil medição), sendo que em nenhuma das categorias foi constatado grau 2.

Os indicadores coletados e seu grau de importância estão representados na Figura 1 e os resultados relacionados à dificuldade de medição estão representados na Figura 2. 
SIBRAGEC - ELAGEC 2019 - de 23 a 25 de Outubro - LONDRINA - PR

Figura 1 - Indicadores coletados da Empresa A - Grau de Importância

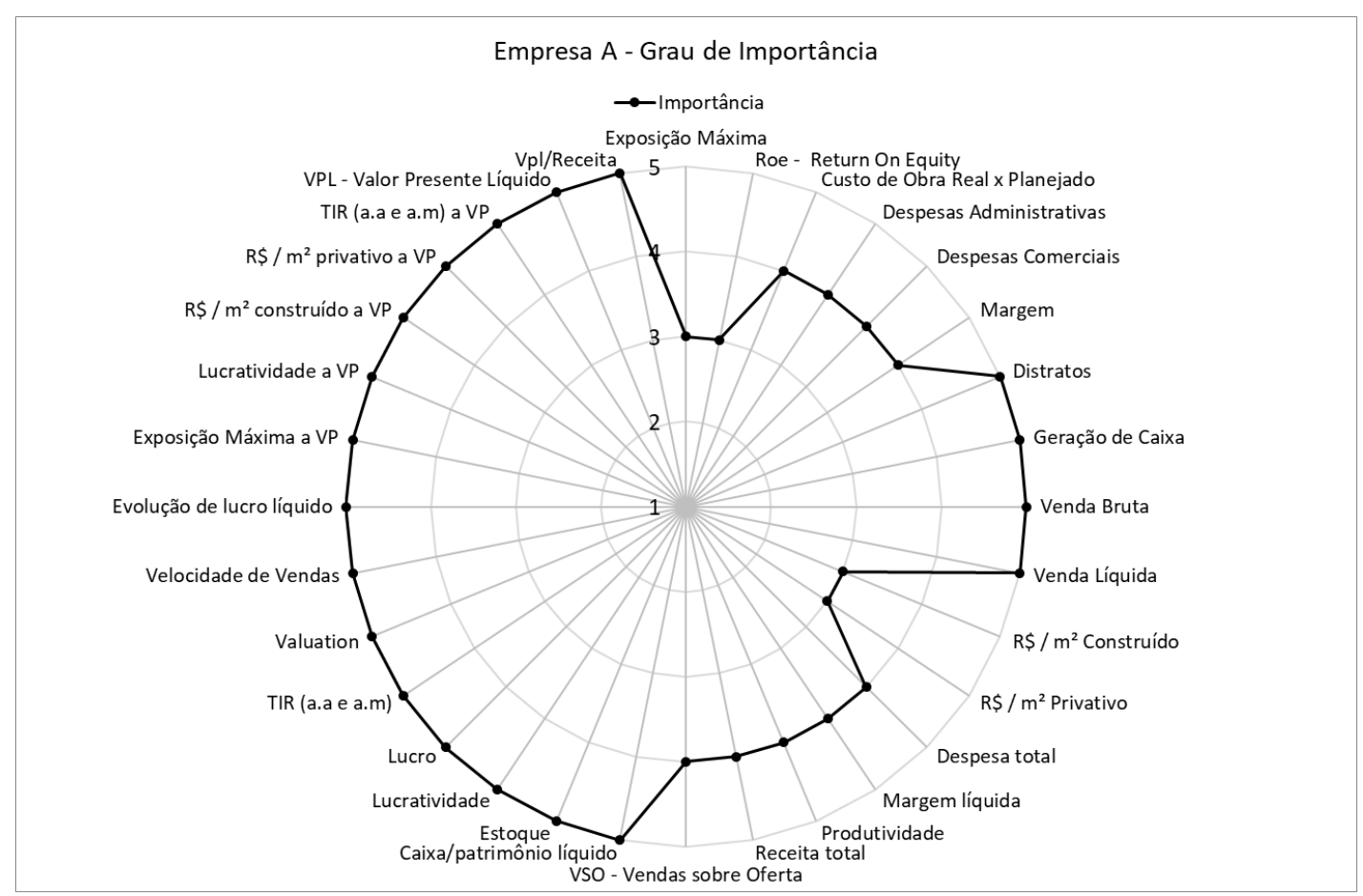

Fonte: Do autor.

Figura 2 - Indicadores coletados da Empresa A - Grau de Dificuldade de Medição

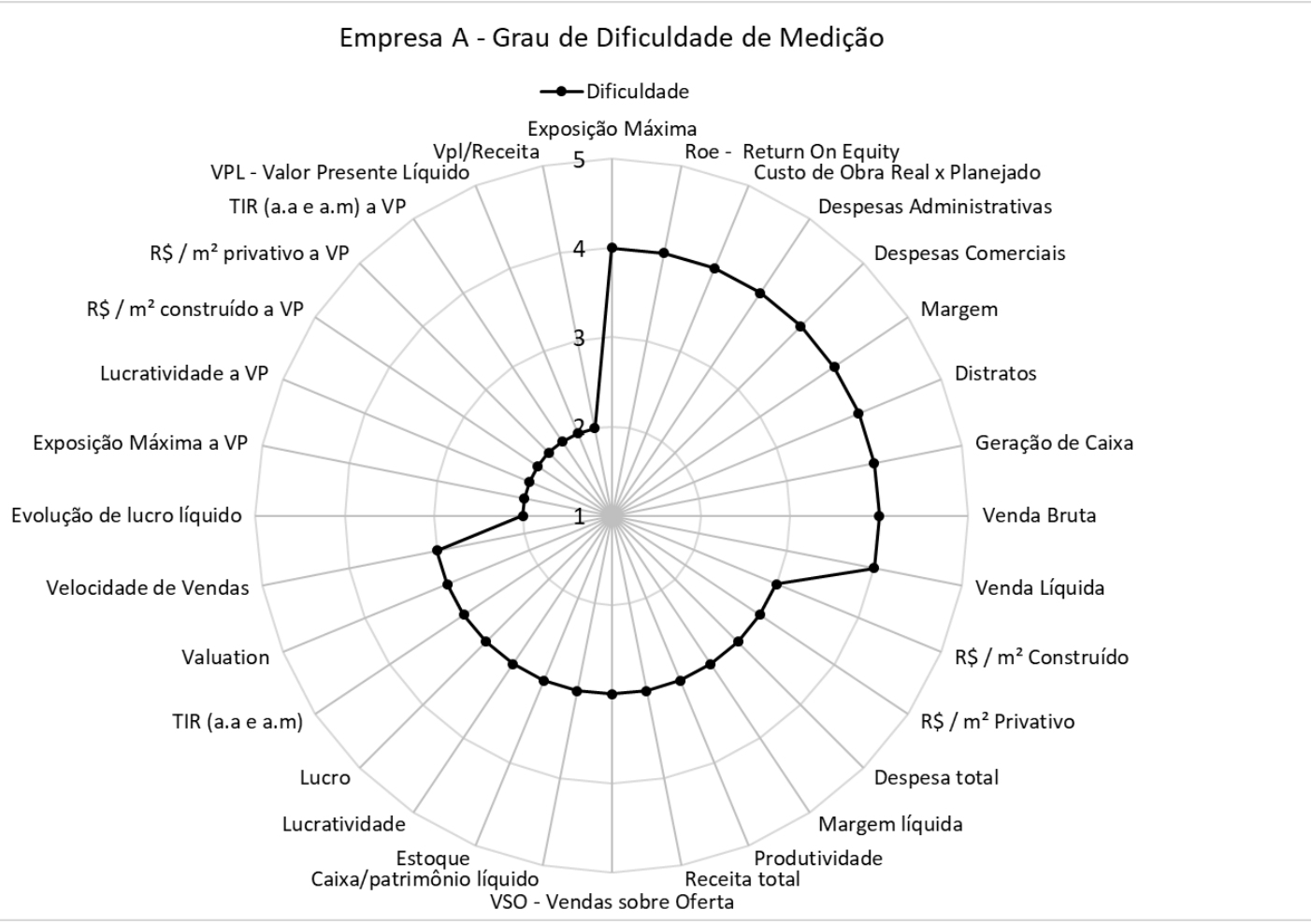

Fonte: Do autor.

Destaca-se que não há indicadores apontados pela empresa com importância menor do que 3 e alguns dos indicadores como Valor Presente (VP) são mais importantes para a tomada de decisão da empresa do que os indicadores nominais. 
Os indicadores Exposição Máxima e o de Retorno sobre o Patrimônio Líquido (ROE) são os indicadores que têm sua efetividade questionável, sendo que o grau de dificuldade de medição é maior do que sua importância para tomada de decisão.

\section{CONCLUSÕES}

Foi possível identificar quais são os indicadores financeiros-chave monitorados para tomada de decisão pela empresa incorporadora e construtora.

A principal dificuldade identificada na medição dos indicadores levantados pela empresa é o excesso de trabalho manual. Um dashboard, contendo todos os indicadores levantados pela empresa poderia compilar os diversos dados e contribuir para decisões estratégicas.

Sugere-se a divisão dos indicadores em processos da empresa, o que facilitaria o contato com o gestor responsável pelo monitoramento destes indicadores.

Em trabalhos futuros sugere-se a análise de multicasos de incorporadoras com intuito de propor um sistema de indicadores padronizado, permitindo a comparação de desempenho entre as empresas, o que poderia auxiliar na tomada de decisão, no estabelecimento de metas para melhoria contínua e na promoção de um mercado mais competitivo frente às necessidades dos clientes internos e externos, parceiros e da sociedade.

\section{REFERÊNCIAS}

ADEMI. Avaliação do Mercado Imobiliário na cidade de Goiânia em dezembro de 2017.

Disponibilizado pela empresa do estudo de caso.

BARBOSA, A. S. Uso de Indicadores de Desempenho nas empresas construtoras brasileiras: diagnóstico e orientações para utilização. São Carlos, 2010. 273 f. Tese de Doutorado em Engenharia de Produção - Escola de Engenharia, Universidade de São Paulo, São Carlos, 2015.

BELLEN, H.V. Indicadores de Sustentabilidade: Uma Análise Comparativa. Rio de Janeiro, Editora FGV, 2005.

CÂNDIDO, L. F. Análise de sistemas de medição de desempenho na construção civil: oportunidades de melhoria a partir da literatura e da experiência de construtoras cearenses. Dissertação (Mestrado em Engenharia Civil) - Programa de Pós-graduação em Engenharia Civil: estruturas e construção civil, Universidade Federal do Ceará (UFC), Fortaleza. 2015.

CELLARD, A. A análise documental. In: A pesquisa qualitativa: enfoque epistemológicos e metodológicos. Petrópolis, RJ: Vozes, 2010. P. 295-316, 2010.

KENNERLEY, M; NEELY, A. A framework of the factors affecting the evolution of performance measurement systems. International Journal of Operations \& Production Management, v. 22, n 11, p 1222$1245,2002$.

LIMA, A.C.C e PONTE, V.M.R. Um estudo sobre os fatores-chave na implantação de modelos de medição do desempenho organizacional. Revista de Administração e Contabilidade da Unisinos. Pág. 285296Set/Dez 2006.

NEELY, A.; BOURNE, M. Why Measurement Initiatives Fail. Measuring Business Excellence, v. 4, n.4, 2000.

ROSA, F. S.; ENSSLIN, S. R.; ENSSLIN, L. Avaliação de Desempenho: processo de revisão sistêmica de literatura internacional. Revista Produção Online, v.13, n. 2, p. 390-416, 2013.

SINDUSCON-GO. Tabela de Índices Econômicos - 2018. Disponível em: <http://www.sinduscongoias.com.br/arquivos/download/indicadores/RQ-30_junho-2018.pdf>Acesso em 28 de novembro de 2018. 


\section{APÊNDICE A - ROTEIRO DE ENTREVISTA}

Para o desenvolvimento desta pesquisa fica garantido o sigilo das informações relativas às empresas entrevistadas. As entrevistas podem ser gravadas, desde que com o consentimento do entrevistado, para agilizar o processo. O pesquisador se compromete a encaminhar as empresas interessadas um exemplar do arquivo final da pesquisa.

\section{PARTE 1 - CARACTERIZAÇÃO DA EMPRESA}

A primeira parte da entrevista tem como objetivo colher informações sobre a empresa em relação ao seu posicionamento no mercado, filosofia gerencial, iniciativas de melhorias e porte. Essas informações são importantes para caracterizar melhor a empresa e estabelecer uma relação de confiança entre o entrevistador e o entrevistado.

1. Há quanto tempo a empresa atua no mercado? Fale mais sobre o histórico.

2. Quantas obras a empresa já realizou? Atualmente, quantas estão em fase de construção? Essas obras são semelhantes (mesmo porte, tipologia)?

3. Que tipo de certificações e a quanto tempo a empresa as possui?

( ) ISO

( ) PBQP-H, Nível

( ) Outra. Qual?

\section{PARTE 2 - CARACTERÍSTICAS SOBRE MEDIÇÃO DE DESEMPENHO E SEU USO}

A segunda parte desta entrevista traz informações sobre como a empresa realiza a medição de desempenho, qual a visão da empresa sobre o assunto e qual o papel que o seu sistema cumpre.

4. Qual o significado de desempenho para sua empresa?

5. Quais são os processos críticos da empresa e de seus empreendimentos? Eles são mapeados?

6. Quais os indicadores coletados pela sua empresa sistematicamente? Há quanto tempo são coletados? Qual a frequência?

7. Existem procedimentos definidos para coleta e processamento dos indicadores de desempenho? (solicitar as planilhas? Manuais de uso dos indicadores)

8. Como as pessoas responsáveis pela coleta e processamento dos dados foram instruídas?

9. Existe alguma estratégia para incentivar as pessoas a coletar os dados? É necessário às vezes cobrar para que as pessoas coletem os dados? existe algum procedimento para verificar se as pessoas estão coletando corretamente os dados?

10. Como são apresentadas as informações? Existem relatórios específicos? Qual o formato e conteúdo destes relatórios? (solicitar um de cada modelo de apresentação)

11. Qual a principal dificuldade que a empresa tem para revisar o seu sistema de medição?

12. Como foi feita a seleção dos indicadores da sua empresa?
a) ( ) a partir da estratégia
b) ( ) a partir de sistemas de gestão de qualidade
c) ( ) a partir de clubes de benchmarking setorial
d) ( ) a partir dos processos críticos
e) ( ) a partir de consultorias externas
f) ( ) a partir da literatura
g) ( ) a partir de certificações, qual (is)?
h) ( ) outro, qual?

13. O Sistema de Medição de Desempenho (SMD) da empresa, incluindo indicadores e metas, é periodicamente revisado?

a) ( ) O sistema é estático, ou seja, não há procedimentos para revisá-lo.

b) ( ) Avalia se os indicadores ainda refletem os objetivos organizacionais.

c) Qual a frequência? 
a) ( ) Avalia a utilidade, eficiência e consistência do sistema como um todo. Qual a frequência?

\section{PARTE 3 - INDICADORES FINANCEIROS}

A terceira parte desta entrevista diz respeito às características sobre os processos desenvolvidos para medição dos Indicadores Financeiros. Tem por objetivo levantar o que é monitorado, formulações, como e quais as ferramentas utilizadas, não necessitando de valores em si.

1. Qual a importância dos indicadores financeiros para a sua empresa?

2. Em sua opinião o uso apenas de indicadores financeiros é o suficiente para a tomada de decisões na empresa?

3. Indique qual o grau de importância você afere a cada situação de medição de desempenho (A) e qual o grau de utilização em sua empresa (B). Sendo 1 sem importância (A)/ pouca dificuldade de medição (B) e 5 extremamente importante (A)/ muita dificuldade de medição (B).

\begin{tabular}{|c|c|c|c|c|c|c|c|c|c|c|c|c|}
\hline \multirow{3}{*}{ INDICADORES } & \multicolumn{2}{|c|}{ MENSURADO? } & \multirow{2}{*}{\multicolumn{5}{|c|}{$\begin{array}{c}\text { A } \\
\text { GRAU DE } \\
\text { IMPORTÂNCIA }\end{array}$}} & \multirow{2}{*}{\multicolumn{5}{|c|}{$\begin{array}{c}\text { B } \\
\text { GRAU DE } \\
\text { DIFICULDADE }\end{array}$}} \\
\hline & \multirow[t]{2}{*}{ SIM } & NÃO & & & & & & & & & & \\
\hline & & AL $\mathbf{E}$ & \multicolumn{5}{|c|}{ TÃ̃O } & & & & & \\
\hline Venda Líquida & $($ ) & ( ) & 1 & 2 & 3 & 4 & 5 & 1 & 2 & 3 & 4 & 5 \\
\hline Venda Bruta & ( ) & ( ) & 1 & 2 & 3 & 4 & 5 & 1 & 2 & 3 & 4 & 5 \\
\hline Rescisão Contratual & ( ) & ( ) & 1 & 2 & 3 & 4 & 5 & 1 & 2 & 3 & 4 & 5 \\
\hline Margem & ( ) & ( ) & 1 & 2 & 3 & 4 & 5 & 1 & 2 & 3 & 4 & 5 \\
\hline Despesas Comerciais & ( ) & ( ) & 1 & 2 & 3 & 4 & 5 & 1 & 2 & 3 & 4 & 5 \\
\hline Despesas Administrativas & ( ) & ( ) & 1 & 2 & 3 & 4 & 5 & 1 & 2 & 3 & 4 & 5 \\
\hline Evolução de lucro líquido & $($ ) & ( ) & 1 & 2 & 3 & 4 & 5 & 1 & 2 & 3 & 4 & 5 \\
\hline Margem líquida & ( ) & ( ) & 1 & 2 & 3 & 4 & 5 & 1 & 2 & 3 & 4 & 5 \\
\hline Produtividade & ( ) & ( ) & 1 & 2 & 3 & 4 & 5 & 1 & 2 & 3 & 4 & 5 \\
\hline Geração de Caixa & ( ) & $($ ) & 1 & 2 & 3 & 4 & 5 & 1 & 2 & 3 & 4 & 5 \\
\hline VSO - Vendas sobre Oferta & ( ) & $($ ) & 1 & 2 & 3 & 4 & 5 & 1 & 2 & 3 & 4 & 5 \\
\hline $\begin{array}{l}\text { ROE - Return On Equity } \\
\text { (em português: Retorno } \\
\text { sobre o Patrimônio) }\end{array}$ & ( ) & ( ) & 1 & 2 & 3 & 4 & 5 & 1 & 2 & 3 & 4 & 5 \\
\hline Caixa/patrimônio líquido & ( ) & ( ) & 1 & 2 & 3 & 4 & 5 & 1 & 2 & 3 & 4 & 5 \\
\hline $\begin{array}{l}\text { Custo de obra } \text { Real x } \\
\text { Planejado }\end{array}$ & )$^{(}$ & ( ) & 1 & 2 & 3 & 4 & 5 & 1 & 2 & 3 & 4 & 5 \\
\hline Outro? & & & 1 & 2 & 3 & 4 & 5 & 1 & 2 & 3 & 4 & 5 \\
\hline Outro? & & & 1 & 2 & 3 & 4 & 5 & 1 & 2 & 3 & 4 & 5 \\
\hline Outro? & & & 1 & 2 & 3 & 4 & 5 & 1 & 2 & 3 & 4 & 5 \\
\hline Outro? & & & 1 & 2 & 3 & 4 & 5 & 1 & 2 & 3 & 4 & 5 \\
\hline Outro? & & & 1 & 2 & 3 & 4 & 5 & 1 & 2 & 3 & 4 & 5 \\
\hline Outro? & & & 1 & 2 & 3 & 4 & 5 & 1 & 2 & 3 & 4 & 5 \\
\hline
\end{tabular}


Outro?

\begin{tabular}{|c|c|c|c|c|c|c|c|c|c|c|c|c|}
\hline \multicolumn{3}{|l|}{ Outro? } & \multirow{2}{*}{\multicolumn{2}{|c|}{$\begin{array}{l}1 \\
1\end{array}$}} & \multirow{2}{*}{$\begin{array}{l}3 \\
3\end{array}$} & \multirow{2}{*}{\multicolumn{2}{|c|}{$\begin{array}{r}45 \\
45\end{array}$}} & \multirow{2}{*}{$\int_{1}^{1}$} & \multirow{2}{*}{$\begin{array}{l}2 \\
2\end{array}$} & \multirow{2}{*}{$\begin{array}{l}3 \\
3\end{array}$} & \multirow{2}{*}{\multicolumn{2}{|c|}{$\begin{array}{l}45 \\
45\end{array}$}} \\
\hline Outro? & & & & & & & & & & & & \\
\hline \multicolumn{13}{|c|}{ VIABILIDADE } \\
\hline $\begin{array}{l}\text { VPL - Valor Presente } \\
\text { Líquido }\end{array}$ & ( ) & ( ) & 1 & 2 & 3 & 4 & 5 & 1 & 2 & 3 & 4 & 5 \\
\hline VPL/Receita & ( ) & ( ) & 1 & 2 & 3 & 4 & 5 & 1 & 2 & 3 & 4 & 5 \\
\hline Exposição Máxima & ( ) & ( ) & 1 & 2 & 3 & 4 & 5 & 1 & 2 & 3 & 4 & 5 \\
\hline TIR (a.a. e a.m.) & ( ) & ( ) & 1 & 2 & 3 & 4 & 5 & 1 & 2 & 3 & 4 & 5 \\
\hline Lucratividade & ( ) & ( ) & 1 & 2 & 3 & 4 & 5 & 1 & 2 & 3 & 4 & 5 \\
\hline $\mathrm{R} \$ / \mathrm{m}^{2}$ construído & ( ) & ( ) & 1 & 2 & 3 & 4 & 5 & 1 & 2 & 3 & 4 & 5 \\
\hline $\mathrm{R} \$ / \mathrm{m}^{2}$ privativo & ( ) & ( ) & 1 & 2 & 3 & 4 & 5 & 1 & 2 & 3 & 4 & 5 \\
\hline Outro? & & & 1 & 2 & 3 & 4 & 5 & 1 & 2 & 3 & 4 & 5 \\
\hline Outro? & & & 1 & 2 & 3 & 4 & 5 & 1 & 2 & 3 & 4 & 5 \\
\hline Outro? & & & 1 & 2 & 3 & 4 & 5 & 1 & 2 & 3 & 4 & 5 \\
\hline Outro? & & & 1 & 2 & 3 & 4 & 5 & 1 & 2 & 3 & 4 & 5 \\
\hline Outro? & & & 1 & 2 & 3 & 4 & 5 & 1 & 2 & 3 & 4 & 5 \\
\hline Outro? & & & 1 & 2 & 3 & 4 & 5 & 1 & 2 & 3 & 4 & 5 \\
\hline Outro? & & & 1 & 2 & 3 & 4 & 5 & 1 & 2 & 3 & 4 & 5 \\
\hline Outro? & & & 1 & 2 & 3 & 4 & 5 & 1 & 2 & 3 & 4 & 5 \\
\hline Outro? & & & 1 & 2 & 3 & 4 & 5 & 1 & 2 & 3 & 4 & 5 \\
\hline Outro? & & & 1 & 2 & 3 & 4 & 5 & 1 & 2 & 3 & 4 & 5 \\
\hline
\end{tabular}

1. Como vocês identificam a necessidade destes indicadores financeiros (a partir do sistema da qualidade, estratégias, processos críticos)?

2. Quem foi responsável pela seleção /escolha dos indicadores financeiros? Foram definidos os responsáveis para coleta, para processamento e para a análise?

3. A empresa tem detectado alguma dificuldade para definição de quais os indicadores financeiros a serem medidos? (pedir para especificar qual(is))

4. Em sua opinião, o que poderia ser feitos para que essas dificuldades fossem eliminadas?

5. Alguns indicadores são considerados como "atrasados", pois refletem um resultado atingido em um determinado período (mês anterior, por exemplo). É o caso de vários indicadores financeiros, como o custo real da obra (baseado nos sistemas de contabilidade da empresa). Como a empresa lida com essa situação?

6. Qual a principal dificuldade que a empresa tem para realizar a coleta e o processamento dos dados referentes aos indicadores financeiros? 